\title{
SUBJECTIVE GLOBAL NUTRITIONAL ASSESSMENT: APPLICABILITY IN CHILDREN AND ADOLESCENTS WITH MALIGNANT TUMORS
}

\section{Kellen Benites Nemetz ${ }^{1}$, Laura de Carvalho Bastos Domingues², Lauro José Gregianin ${ }^{1,3}$, Luciane Beitler da Cruz ${ }^{3}$}

\section{ABSTRACT}

Clin Biomed Res. 2021;41(3):212-219

1 Programa de Pós-graduação em Saúde da Criança e do Adolescente, Universidade Federal do Rio Grande do Sul. Porto Alegre, RS, Brasil.

2 Pontifícia Universidade Católica do Rio Grande do Sul. Porto Alegre, RS, Brasil.

3 Serviço de Oncologia Pediátrica, Hospital de Clínicas de Porto Alegre. Porto Alegre, RS, Brasil.

Corresponding author: Kellen Benites Nemetz kellenb.nutri@gmail.com Faculdade de Medicina, Universidade Federal do Rio Grande do Sul Rua Ramiro Barcelos, 2400 90035-002, Porto Alegre, RS, Brasil.
Introduction: This study investigated the applicability of the Subjective Global Nutritional Assessment (SGNA) tool to evaluate the nutritional status of pediatric cancer patients.

Methods: This was a multicenter, observational cohort study of infants, children, and adolescents diagnosed with malignant tumors. Participants were evaluated the moment they were diagnosed with a malignant tumor (EV1) and the third month of treatment (EV2). Objective data were collected and the SGNA questionnaire was applied. Correlation between the methods was performed using the Kendall test.

Results: We evaluated 216 patients at EV1 and 172 patients at EV2. During EV1, $7 \%$ of patients presented with some degree of malnutrition, according to objective measures, and $35.7 \%$ according to the SGNA. During EV2, they presented $6.4 \%$ and $26.8 \%$, respectively. The SGNA showed ability to diagnose more malnutrition than objective indicators and the agreement found between both methods was moderate and weak. We observed a significant correlation between the SGNA and the nutritional indicators $(p=<0.002)$, thus proving its efficacy in assessing nutritional status.

Conclusion: The SGNA was applicable for evaluating the nutritional status of children and adolescents diagnosed with malignant tumors, and effective in tracking malnutrition prevalence when compared to objective nutritional assessment methods.

Keywords: Tumor; Pediatrics; Nutritional status; Nutritional assessment

\section{INTRODUCTION}

Noncommunicable diseases (NCDs) are the leading cause of morbidity and mortality worldwide. Cancer is an NCD and represents a major public health problem in both developed and developing countries ${ }^{1}$. In Brazil, an estimated 420,000 new cancer cases were diagnosed between 2018 and 2019. For young children and adolescents, there were an estimated 12,500 new cases. According to these estimates, the southeast and northeast regions showed the highest incidence $(5,300$ and 2,900 , respectively), followed by the midwest, with 1800 new cases, the southern region, with 1,300, and the northern region, with 1,200 new cases $^{1-3}$.

Malnutrition in children and adolescents undergoing cancer treatment is a poor prognostic factor. Cancer treatment itself predisposes patients to loss of appetite, increased basal metabolism, fever, and infection, which, in turn, may favor depletion of nutritional status (NS), thus delaying antineoplastic treatment and increasing the average length of hospital stay ${ }^{4-8}$.

Our group observed that the NS assessment protocol in pediatric cancer patients is based only on objective parameters. However, objective measures in the clinical setting are at times difficult to perform and may be biased, such as in the presence of large tumors or during periods of hyperhydration ${ }^{9}$. Thus, there is a need for new nutritional assessment tools that evaluate children and 
adolescents diagnosed with cancer beyond objective measures to better screen for nutritional risk.

In 1987, Detsky et al. ${ }^{10}$, recommended the Subjective Global Assessment (SGA) evaluation for adults. Subsequently, in 2007, Secker \& Jeejeebhoy ${ }^{11}$ proposed another tool called the Subjective Global Nutritional Assessment (SGNA) for pediatric populations. This method was proven valid for evaluating children and adolescents at nutritional risk associated with postoperative complications and longer hospital stays ${ }^{11}$. In 2015, Carniel et al. ${ }^{12}$ validated this instrument for the Brazilian population, and it has since been tested in a general pediatric population at a hospital in southern Brazil. The SGNA was proven a valid and reliable method for the evaluation of NS when compared to traditional methods based only on anthropometric parameters ${ }^{11,12}$. Since then, the SGNA was also tested in different pediatric subspecialties to verify its effectiveness in screening for malnutrition, similarly to the objective nutritional assessment method. The subjective evaluation has been effective in the perception of nutritional changes, working as an auxiliary method for the nutrition professional in the identification of patients who would benefit from early nutritional intervention ${ }^{13,14}$. To improve knowledge of this method, the present study tested whether the SGNA could be applied to a pediatric oncology population, comparing the SGNA scores to the anthropometric parameters currently used in the clinical setting. Thus, the purpose of this study was to evaluate the applicability of the SGNA questionnaire in evaluating the NS of infants, children, and adolescents soon after the diagnosis of a malignant tumor and during 3 months of treatment.

\section{METHODS}

\section{Study design and location}

This was a multicentric, observational cohort study with primary data collection, which was conducted at the Pediatric Oncology Services of the Hospital de Clínicas de Porto Alegre, the Hospital da Criança Santo Antônio, and the Hospital da Criança Conceição in Porto Alegre, state of Rio Grande do Sul.

\section{Population}

Patients between 30 days and 18 years of age, of both sexes, who were diagnosed with malignant tumors and began treatment in either one of the 3 hospitals, were invited to participate in the study. Exclusion criteria included (1) diagnosis of recurring malignant tumors, (2) terminal illness, (3) pregnancy, (4) delayed neuropsychomotor development, (5) underlying chronic pathologies (congenital malformations, innate metabolism errors, heart disease, neuropathy, liver disease), (6) impossibility to collect anthropometric data, and (7) not being able to speak Portuguese.

\section{Sample size}

A sample of 216 patients was collected continuously from December 2016 to December 2018. The study sample size was calculated using WINPEPI, version 11.43 . Considering a $90 \%$ statistical power, significance level of $5 \%$, and a $\mathbf{- 0 . 2 3}$ (Kendall) correlation obtained in the SGNA validation, according to Carniel et al. ${ }^{12}$, the minimum total sample size should be 210 subjects, already accounting for $10 \%$ of losses and refusals.

\section{Study variables}

Demographic information and identification were collected from participants and their legal guardians. Weight and height measurements were performed according to the Technical Standard of the Food and Nutrition Surveillance System (Norma Técnica do Sistema de Vigilância Alimentar e Nutricional) ${ }^{15}$, with INMETRO-certified digital scales and stadiometers. Circumference and skinfolds were measured according to the Brazilian Society of Pediatrics Manual ${ }^{16}$. Arm circumference was measured with an inelastic, retractable tape measure, in millimeters; and tricipital and subscapular skinfold thickness were measured with a Lange (US) or Cescorf (Porto Alegre, Brazil) scientific plicometer. To obtain the values of upper arm muscle circumference, the formula proposed by Frisancho was employed ${ }^{17}$. The measures weightfor-age (W/A), height-for-age $(H / A)$, weight-forheight $(\mathrm{W} / \mathrm{H})$, and body mass index-for-age (BMI/A) for children under 5 years of age were calculate using the World Health Organization (WHO) Anthro software (version 3.2.2), and the WHO Anthro Plus software (version 1.0.4), for children 5 years of age or older. The percentiles and Z-scores were interpreted according to cutoff points defined by the World Health Organization ${ }^{16,18,19}$. The objective nutritional assessment was performed by analyzing the set of nutritional indicators mentioned above.

The "SGNA Questionnaire for Infants and Children Under 2 Years" and the "SGNA Questionnaire for Adolescents and Children Over 2 Years" were applied to patients and/or the parent/guardian to collect data from clinical history, weight and height history, parents' height, food intake, and recent changes, as well as physical examination (muscle mass, subcutaneous fat, and edema). Children and adolescents were classified as well nourished, moderately malnourished, or severely malnourished. The questionnaires and the scores for each classification are attached to the instrument validation article $^{12}$.

\section{Logistics}

Data collection, and objective and subjective nutritional assessments were performed by 2 nutritionists, who were familiar with the same research study protocol. The first evaluation (EV1) was performed soon after 
Nemetz et al.

the diagnosis of malignant tumor in the patient's primary hospital. The second evaluation (EV2) was performed during the third month of treatment, and occurred either during hospitalization, during outpatient appointments at the patient's primary hospital, or at private clinics. Data regarding EV1 and EV2 could be collected within 15 days of the established data collection time points.

\section{Statistical analysis}

Statistical analysis was performed using the SPSS software (Statistical Package for Social Sciences), version 21.0. Quantitative variables were described by their mean and standard deviation or median and interquartile range; and the Shapiro-Wilk test was performed to assess normal distribution. Categorical variables were described by absolute and relative frequencies. To verify association between continuous variables, the Spearman correlation coefficient and the Student's $t$ test for paired samples were employed. Proportions between groups were compared using Pearson's chi-square test with a prevalence ratio of $95 \%$. The association between the assessment methods was evaluated by the Kendall rank correlation coefficient. Comparisons between the categorical variables during both time points, labelled as EV1 and EV2, were performed using the McNemar test. In all analyses, significance was established at $5 \%$.

\section{Ethical considerations}

This study was performed according to the national ethics guidelines (NR 466/2012) of the Brazilian National Health Council ${ }^{20}$. The Research Ethics Committees of each participating hospital evaluated and approved the study design (Grupo Hospitalar Conceição: approval number 1.931.294; Hospital de Clínicas de Porto Alegre: approval number 1.815.232; Hospital da Criança Santo Antônio: approval number 1.878.494). Signed informed consent was obtained by all study participants (patients or their legal guardians).

\section{RESULTS}

A total of 216 assessments were performed at the moment of diagnosis of a malignant tumor (EV1) and 172 evaluations were performed during the third month of treatment (EV2).

Most patients were aged 2-10 years and boys were more prevalent than girls in both EV1 and EV2. The most prevalent diagnosis was lymphohematopoietic neoplasms. Most patients in EV1 reported hypocaloric food intake, one or more gastrointestinal symptoms, and restriction to strenuous activities. During EV2, there were improvements in all of these conditions, but only the improvement in gastrointestinal symptoms was statistically significant $(p=0.027)$, as described in Table 1.

Table 1: Clinical and nutritional characteristics at diagnosis (EV1) and after 3 months of treatment (EV2).

\begin{tabular}{|c|c|c|c|}
\hline Indicators & EV1 & EV2 & $p$ \\
\hline Sample size, $n$ & 216 & 172 & \\
\hline Age, months & $72[31-140]$ & $76[37-146]$ & 0.135 \\
\hline$<2$ years & $38(17.6 \%)$ & $26(15.1 \%)$ & \\
\hline $2-10$ years & $118(54.6 \%)$ & $97(56.4 \%)$ & \\
\hline$>10$ years & $60(27.8 \%)$ & $49(28.5 \%)$ & \\
\hline Sex & & & - \\
\hline Female & $87(40.3 \%)$ & $69(40.1 \%)$ & \\
\hline Male & $129(59.7 \%)$ & $103(59.9 \%)$ & \\
\hline Diagnosis & & & - \\
\hline Lymphohematopoietic neoplasms & $143(66.2 \%)$ & $113(65.7 \%)$ & \\
\hline Neuroblastoma & $19(8.8 \%)$ & $15(8.7 \%)$ & \\
\hline Wilms' tumor & $15(6.9 \%)$ & $13(7.6 \%)$ & \\
\hline Retinoblastoma & $12(5.6 \%)$ & $9(5.2 \%)$ & \\
\hline Bone tumors & $11(5.1 \%)$ & $10(5.8 \%)$ & \\
\hline Other abdominal tumors & $6(2.8 \%)$ & $5(2.9 \%)$ & \\
\hline Soft tissue sarcoma & $5(2.3 \%)$ & $4(2.3 \%)$ & \\
\hline Germ cell tumors & $4(1.9 \%)$ & $2(1.2 \%)$ & \\
\hline Nasopharyngeal tumors & $1(0.5 \%)$ & $1(0.6 \%)$ & \\
\hline Food consumption & & & 0.064 \\
\hline Adequate & $95(44 \%)$ & $93(54.1 \%)$ & \\
\hline Hypocaloric & $98(45.4 \%)$ & $59(34.3 \%)$ & \\
\hline Low intake & $23(10.6 \%)$ & $20(11.6 \%)$ & \\
\hline Gastrointestinal symptoms & & & 0.027 \\
\hline No symptoms & $92(42.6 \%)$ & $98(57 \%)$ & \\
\hline One or more symptom, not daily & $105(48.6 \%)$ & $67(39 \%)$ & \\
\hline Several symptoms, daily & $19(8.8 \%)$ & $7(4 \%)$ & \\
\hline
\end{tabular}


Table 1: Clinical and nutritional characteristics at diagnosis (EV1) and after 3 months of treatment (EV2).

\begin{tabular}{|c|c|c|c|}
\hline \multicolumn{3}{|l|}{ Functional capacity } & \multirow[t]{2}{*}{0.297} \\
\hline No dysfunction & 87 (40.3\%) & $86(50 \%)$ & \\
\hline Restricted & $104(48.1 \%)$ & $66(38.4 \%)$ & \\
\hline Little or no activity & $25(11.6 \%)$ & $20(11.6 \%)$ & \\
\hline \multicolumn{3}{|l|}{ Subcutaneous fat loss } & 0.166 \\
\hline No loss/mild loss & $189(87.5 \%)$ & $151(87.8 \%)$ & \\
\hline Moderate loss & $20(9.3 \%)$ & $19(11 \%)$ & \\
\hline Severe loss & $7(3.2 \%)$ & $2(1.2 \%)$ & \\
\hline \multicolumn{3}{|l|}{ Muscle mass loss } & 0.096 \\
\hline No loss/mild loss & $189(87.5 \%)$ & $150(87.2 \%)$ & \\
\hline Moderate loss & $19(8.8 \%)$ & $21(12.2 \%)$ & \\
\hline Severe loss & $8(3.7 \%)$ & $1(0.6 \%)$ & \\
\hline \multicolumn{3}{|l|}{ Edema } & 0.500 \\
\hline None & 215 (99.5\%) & $170(98.8 \%)$ & \\
\hline Moderate & $1(0.5 \%)$ & $2(1.2 \%)$ & \\
\hline Severe & - & - & \\
\hline \multicolumn{3}{|c|}{ Objective nutritional assessment } & 0.588 \\
\hline Severely malnourished & $6(2.8 \%)$ & $3(1.7 \%)$ & \\
\hline Mildly malnourished & $9(4.2 \%)$ & $8(4.7 \%)$ & \\
\hline At risk for low weight & $6(2.8 \%)$ & $9(5.2 \%)$ & \\
\hline Well-nourished & $116(53.7 \%)$ & $96(55.8 \%)$ & \\
\hline At risk for being overweight & $30(13.9 \%)$ & $16(9.3 \%)$ & \\
\hline Overweight & $26(12 \%)$ & $21(12.2 \%)$ & \\
\hline Obese & $21(9.7 \%)$ & $15(8.7 \%)$ & \\
\hline Severely obese & $2(0.9 \%)$ & $4(2.3 \%)$ & \\
\hline \multicolumn{4}{|l|}{ Circumference and skinfolds } \\
\hline \multicolumn{3}{|l|}{$A C(n=189)$} & 1.000 \\
\hline Adequate & $165(87.3 \%)$ & $142(89.9 \%)$ & \\
\hline Below expected & $24(12.7 \%)$ & $16(10.1 \%)$ & \\
\hline \multicolumn{3}{|l|}{ TST $(n=184)$} & 0.549 \\
\hline Adequate & $165(89.7 \%)$ & $141(93.4 \%)$ & \\
\hline Below expected & $19(10.3 \%)$ & $10(6.6 \%)$ & \\
\hline \multicolumn{3}{|l|}{ UAMC $(n=184)$} & 0.581 \\
\hline Adequate & $160(87 \%)$ & $134(89.3 \%)$ & \\
\hline Below expected & $24(13 \%)$ & $16(10.7 \%)$ & \\
\hline \multicolumn{3}{|l|}{ SST $(n=180)$} & 0.065 \\
\hline Adequate & $164(91.1 \%)$ & $141(96.6 \%)$ & \\
\hline Below expected & $16(8.9 \%)$ & $5(3.4 \%)$ & \\
\hline \multicolumn{3}{|l|}{ SGNA } & 0.426 \\
\hline Well-nourished & $139(64.3 \%)$ & $126(73.2 \%)$ & \\
\hline Moderately malnourished & $65(30.1 \%)$ & $39(22.7 \%)$ & \\
\hline Severely malnourished & $12(5.6 \%)$ & $7(4.1 \%)$ & \\
\hline
\end{tabular}

CNS: Central nervous system; SGNA: Subjective global nutritional assessment; AC: Arm circumference, adequate if percentile > 5; TST: Tricipital skinfold thickness, adequate if percentile > 15; UAMC: Upper arm muscle circumference, adequate if percentile > 5; SST: Subscapular skinfold thickness, adequate if percentile > 15. [ ]: Data presented as median P50 (P25 - P75); ( ): Data presented as absolute and relative frequencies.

With regards to the physical examination, we did not observe any loss of subcutaneous fat or muscle mass and edema for most patients in both evaluations.

In relation to nutrition diagnosis, it was noted that, at the time of EV1 and EV2, most patients were well nourished, according to both objective and subjective parameters. At the time of diagnosis (EV1), $7 \%(n=15)$ of the patients had some degree of malnutrition according to the objective nutritional assessment, and $35.7 \%(n=77)$ according to the subjective nutritional assessment. During the third month of treatment (EV2), there was an increase in percentiles related to perimeter and skin folds, according to the objective and subjective evaluations. At the time of EV2, $6.4 \%(n=11)$ of patients were malnourished, according to the objective nutritional assessment and $26.8 \%(n=46)$, according to the SGNA. The clinical and nutritional characteristics of EV1 and EV2 are described in Table 1.

Of the 216 patients included in EV1, there were $20 \%$ of losses at EV2, since 22 patients were not hospitalized and had no appointments within the stipulated time period. Eleven patients died within 3 months, 4 patients continued treatment in another 
hospital, 2 patients were over 18 years old, 2 refused to attend EV2, 1 was restricted to bed, 1 had already completed treatment, and 1 patient's parents chose to interrupt treatment. Of the 172 patients remaining for EV2 evaluation, 47 had their EV1 and EV2 evaluations completed by different researchers.

To analyze the evolution of each patient's nutritional status, only the patients evaluated at both moments $(n=172)$ were considered. There was an improvement in subjective and objective parameters, as shown in Table 2. According to the McNemar test and Student's $t$-test, there was no significant difference between the objective and subjective nutritional assessments comparing EV1 and EV2.

The results of the correlation analysis between the methods are described in Table 3.

Table 2: Change in nutritional status during the first 3 months after diagnosis.

\begin{tabular}{|c|c|c|c|}
\hline Nutritional status classification $(n=172)$ & EV1 & EV2 & $p$ \\
\hline \multicolumn{4}{|l|}{ Anthropometric indicators } \\
\hline Z-Score Weight-for-height & $0.55 \pm 1.22^{\mathrm{A}}$ & $0.36 \pm 1.20^{A}$ & 0.100 \\
\hline Z-Score Weight-for-age & $0.33 \pm 1.31^{\mathrm{A}}$ & $0.24 \pm 1.42^{\mathrm{A}}$ & $0.151^{\circ}$ \\
\hline Z-Score Height-for-age & $-0.09 \pm 1.17^{A}$ & $-0.19 \pm 1.18^{\mathrm{A}}$ & 0.003 \\
\hline Z-Score BMI-for-age & $0.49 \pm 1.34^{\mathrm{A}}$ & $0.48 \pm 1.46^{\mathrm{A}}$ & $0.804^{\circ}$ \\
\hline \multicolumn{4}{|l|}{ Subjective Global Nutritional Assessment } \\
\hline Well-nourished & $115(66.5 \%)^{\mathrm{B}}$ & $126(73.2 \%)^{\mathrm{B}}$ & \\
\hline Moderately malnourished & $49(28.9 \%)^{B}$ & $39(22.7 \%)^{B}$ & \\
\hline Severely malnourished & $8(4.6 \%)^{\mathrm{B}}$ & $7(4.1 \%)^{\mathrm{B}}$ & \\
\hline
\end{tabular}

BMI: Body mass index. Data are presented as absolute and relative frequencies. A: Data are presented as mean \pm standard deviation; B: Data are presented as absolute and relative frequencies; $p \leq 0.05$ : denotes statistically significant results; C: Student's t-test; $D$ : McNemar test.

Table 3: Correlation between data obtained from the SGNA and objective measurements.

\begin{tabular}{|c|c|c|c|c|}
\hline Indicators & $\mathbf{N}$ & Objective measurements & r Kendall & $p$ \\
\hline \multicolumn{5}{|l|}{ EV1 } \\
\hline $\mathrm{W} / \mathrm{H}$ & 91 & $0.47 \pm 1.26^{\mathrm{B}}$ & $-0.304^{* *}$ & $0.002^{* *}$ \\
\hline W/A & 156 & $0.28 \pm 1.34^{\mathrm{B}}$ & $-0.260^{*}$ & $0.001^{*}$ \\
\hline $\mathrm{H} / \mathrm{A}$ & 216 & $0.11 \pm 1.17^{\mathrm{B}}$ & $-0.280^{*}$ & $<0.001^{*}$ \\
\hline BMI/A & 216 & $0.51 \pm 1.39^{\mathrm{B}}$ & $-0.287^{*}$ & $<0.001^{*}$ \\
\hline $\mathrm{AC}$ & 180 & $19(16-24)^{A}$ & $0.459^{* *}$ & $<0.001^{\star *}$ \\
\hline TST & 180 & $10(7-15)^{A}$ & $0.249^{*}$ & $0.001^{*}$ \\
\hline UAMC & 180 & $15(13-19)^{A}$ & $0.447^{* *}$ & $<0.001^{* *}$ \\
\hline SST & 180 & $7(5-10)^{A}$ & $0.292^{*}$ & $<0.001^{*}$ \\
\hline \multicolumn{5}{|l|}{ EV2 } \\
\hline $\mathrm{W} / \mathrm{H}$ & 67 & $0.37 \pm 1.20^{\mathrm{B}}$ & $-0.292^{*}$ & $0.013^{*}$ \\
\hline W/A & 123 & $0.24 \pm 1.42^{\mathrm{B}}$ & $-0.312^{\star *}$ & $<0.001^{* *}$ \\
\hline $\mathrm{H} / \mathrm{A}$ & 172 & $-0.19 \pm 1.18^{B}$ & $-0.162^{*}$ & $0.030^{*}$ \\
\hline $\mathrm{BMI} / \mathrm{A}$ & 172 & $0.48 \pm 1.47^{\mathrm{B}}$ & $-0.197^{*}$ & $0.005^{*}$ \\
\hline $\mathrm{AC}$ & 145 & $20(16-24)^{A}$ & $0.323^{* *}$ & $<0.001^{* *}$ \\
\hline TST & 145 & $11(8-15)^{A}$ & -0.027 & 0.739 \\
\hline UAMC & 145 & $16(14-19)^{\mathrm{A}}$ & $0.293^{*}$ & $<0.001^{*}$ \\
\hline SST & 145 & $8(6-11)^{A}$ & 0.061 & 0.455 \\
\hline
\end{tabular}

SGNA: Subjective global nutritional assessment; W/H: Weight-for-height; W/A: Weight-for-age; H/A: Height-for-age; BMI/A: Body mass indexfor-age; AC: Arm circumference; TST: Tricipital skinfold thickness; UAMC: Upper arm muscular circumference; SST: Subscapular skinfold thickness; EV1: Evaluation at the time of diagnosis; EV2: Evaluation after the third month of treatment. A: Data presented as median P50 (P25 - P75); B: Data presented as average \pm standard deviation; $p \leq 0.05$ : Denotes statistically significant results. Kendall rank correlation coefficient; *: Weak correlation; ${ }^{* *}$ : Moderate correlation. 
On average, the SGNA questionnaire was completed in 10 minutes. There was no correlation and significant difference between age and/or education level of the caregivers with regards to the time taken to answer the SGNA questionnaire, for both EV1 and EV2 evaluations.

\section{DISCUSSION}

The SGNA is a non-invasive, quick-to-apply, low-cost instrument that can be performed at the patient's bedside. This instrument was validated for the general pediatric population and showed significant correlation with the anthropometric measurements currently used for nutritional diagnosis of children and adolescents $(\mathrm{W} / \mathrm{H}, \mathrm{W} / \mathrm{A}, \mathrm{H} / \mathrm{A}, \mathrm{BMI} / \mathrm{A}$, $A C, T S T$, and SST $)^{12}$. The present study indicated a moderate and weak correlation between the SGNA and other anthropometric indicators, assessed at diagnosis (EV1) and during the third month of treatment (EV2). Agreement analysis among the nutritional assessment methods was performed using the Kendall coefficient. In EV1, moderate agreement was found in $\mathrm{W} / \mathrm{H}(9 \%), \mathrm{AC}(21 \%)$, and UAMC $(20 \%)$, and weak agreement was found in all other parameters. In EV2, a moderate agreement between W/A $(10 \%)$ and $A C(10 \%)$ was detected, whereas $\mathrm{W} / \mathrm{H}(8 \%), \mathrm{H} / \mathrm{A}(3 \%), \mathrm{BMI} / \mathrm{A}(4 \%)$, and UAMC $(8 \%)$ demonstrated weak correlations with other anthropometric indicators. In spite of these results, the SGNA remains an important tool for understanding the current nutritional assessment of pediatric cancer patients considering food intake, appetite, and weight loss, among others.

The nutrition diagnosis based on the SGNA and the objective nutritional assessment demonstrated that most patients were well nourished at EV1 and EV2. Nearly all the subjective and objective parameters were stable during EV2. The high prevalence of acute leukemia in this study may have contributed to the large number of well-nourished patients at diagnosis and during the third month of treatment, since leukemia patients present with lower risk of malnutrition, with 5 to $10 \%$ at diagnosis and 0 to $5 \%$ during treatment ${ }^{21}$. A large difference was found between the number of patients diagnosed with some degree of malnutrition using the SGNA assessment compared to objective methods of nutritional assessment. This may be due to the fact that the objective assessment considers only weight, height, and body mass, while the SGNA takes into consideration other parameters that influence nutritional status, such as appetite, functional capacity, and gastrointestinal symptoms.

Studies indicate a decrease in the prevalence of malnutrition, all the while with an increase in sarcopenic obesity and in overweight patients during treatment for malignant tumors. This is associated with a higher risk of presenting minimal residual disease, toxicity associated with adiposity, and disease relapse. Reports also associate this weight gain with a gradual decrease in the release of inflammatory markers and the use of high doses of glucocorticoids ${ }^{22-25}$. A cohort study published in 2015 showed a decrease in the number of malnourished patients $(8.3 \%$ to $4.1 \%)$ and an increase in the number of overweight patients $(4.5 \%$ to $6.6 \%)$ when comparing the NS at diagnosis and during the third month of treatment, which is in agreement with the findings presented herein ${ }^{25}$. Monitoring weight changes during cancer treatment may prevent cancer survivors from developing chronic diseases such as obesity, insulin resistance, dyslipidemia, hypertension, and depression, which in turn increase the risk of cardiovascular disease ${ }^{26-29}$. Strategies to identify patients at nutritional risk, whether for malnutrition or obesity, should be adopted in health services that assist pediatric cancer patients. In this regard, nutrition services, nutritional counseling, and appropriate interventions should be offered to patients and/or their caregivers $8,22,30$.

It is known that evaluations taking into account objective nutritional measures alone may underestimate proper nutritional diagnosis. This justifies the importance of using specific nutritional assessment instruments to better characterize each population, their specific pathology and hospital environment, in addition to objective measures ${ }^{23,31}$. In 2016, an adapted equivalent of the subjective nutritional assessment proposed by Secker \& Jeejeebhoy ${ }^{11}$ was released for use in pediatric cancer patients ${ }^{11,32}$. Subsequently, another article was published with cross-cultural adaptations and instrument validations ${ }^{33}$. The SGNA offers a better assessment of NS, since it investigates changes in body weight, food intake, gastrointestinal symptoms, and functional capacity, as well as physical changes in subcutaneous fat, muscle mass, and edema. Objective assessments alone do not contemplate these changes, which may influence NS.

The limitations found in this study were that some patients and/or guardians had difficulty answering certain questions of the assessment instrument, such as specific food intake. Because of logistics, some patients were not evaluated by the same researcher at both moments of the evaluation. This should be taken into consideration since the SGNA is a subjective evaluation method and therefore depends on the researcher's ability to collect and interpret data.

\section{CONCLUSION}

In this study, the SGNA tool proved to be adequate for assessing the nutritional status of infants, children, 
and adolescents diagnosed with malignant tumors. Since it diagnosed more malnutrition than objective indicators, it seems to be effective in screening for malnutrition in this population, which is important as it allows for early nutritional intervention. Thus, further studies should be conducted to analyze the efficacy of the SGNA as a screening tool for malnutrition. This tool can be part of the routine nutritional assessment for children and adolescents with cancer and should be applied within the first hours of hospitalization, allowing for early and individualized nutritional interventions.

\section{Conflicts of Interest}

The authors declare no conflicts of interest.

\section{Acknowledgements}

We would like to thank all the patients and families who participated in this study.

\section{Note}

Preliminary data from this work has already been published in the journal Clinical \& Biomedical Research (https://doi.org/10.4322/2357-9730.80224).

\section{REFERENCES}

1. World Health Organization, International Agency for Research on Cancer. International Childhood Cancer Day: Much remains to be done to fight childhood cancer [Internet]. Lyon: IARC; 2016 [cited 2019 Oct 19]. Available from: https://www.iarc.fr/wpcontent/uploads/2018/07/pr241_E.pdf

2. Instituto Nacional de Câncer José de Alencar Gomes da Silva, Coordenação de Prevenção e Vigilância. Estimativa 2018: Incidência de Câncer no Brasil [Internet]. Rio de Janeiro: INCA; 2017 [cited 2019 Oct 21]. Available from: https://rbc.inca.gov.br/revista/index. php/revista/article/view/115

3. American Cancer Society. The Cancer Atlas [Internet]. 2nd ed. Atlanta: American Cancer Society; 2014 [cited 2019 Oct 19]. Available from:www. cancer.org/canceratlas

4. Peres GB, Valim GS, Silva VL, ElKik RM. Comparação entre métodos de avaliação subjetiva global em oncologia. Cienc Saude (Porto Alegre). 2009;2(1):37-42.

5. Cohen J, Wakefield CE, Laing DG. Smell and Taste Disorders Resulting from Cancer and Chemotherapy. Curr Pharm Des. 2016;22(15):2253-63.

6. Pribnow AK, Ortiz R, Báez LF, Mendieta L, Luna-Fineman S. Effects of malnutrition on treatment-related morbidity and survival of children with cancer in Nicaragua. Pediatr Blood Cancer. 2017;64(11):1-7.

7. Conner JM, Aviles-Robles MJ, Asdahl PH, Zhang FF, Ojha RP. Malnourishment and length of hospital stay among paediatric cancer patients with febrile neutropaenia: a developing country perspective. BMJ Support Palliat Care. 2016;6(3):338-43.
8. Ghafoor T. Prognostic factors in pediatric Hodgkin lymphoma: experience from a developing country. Leuk Lymphoma. 2020;61(2):344-50.

9. Andrassy RJ, Chwals WJ. Nutritional support of the pediatric oncology patients. Nutrition. 1998;14(1):124-9.

10. Detsky AS, McLaughlin JR, Baker JP, Johnston N, Whittaker S, Mendelson RA, et al. What is subjective global assessment of nutritional states? JPEN J Parenter Enteral Nutr. 1987;11(1):8-13.

11. Secker DJ, Jeejeebhoy KN. Subjective Global Nutritional Assessment for children. Am J Clin Nutr. 2007;85(4):1083-9.

12. Carniel MP, Santetti $D$, Andrade JS, Favero BP, Moschen T, Campos PA, et al. Validation of a subjective global assessment questionnaire. J Pediatr (Rio J). 2015;91(6):596-602.

13. Pimenta FS, Oliveira CM, Hattori WT, Teixeira KR. Agreement between Subjective Global Nutritional Assessment and the nutritional assessment of the World Health Organization. J Pediatr (Rio J). 2018;94(6):602-8.

14. Matsuyama M, Bell K, White M, Lawson K, David M, Doolan A, et al. Nutritional Assessment and Status of Hospitalized Infants. J Pediatr Gastroenterol Nutr. 2017;65(3):338-42.

15. Ministério da Saúde (BR), Secretaria de Atenção à Saúde, Departamento de Atenção Básica. Orientações para a coleta e análise de dados antropométricos em serviços de saúde: Norma Técnica do Sistema de Vigilância Alimentar e Nutricional -
SISVAN [Internet]. Brasília, DF: Ministério da Saúde; 2011 [cited 2017 Sep 16]. Available from: http:// bvsms.saude.gov.br/bvs/publicacoes/ orientacoes_coleta_analise_dados_ antropometricos.pdf

16. Sociedade Brasileira de Pediatria, Departamento de Nutrologia. Avaliação nutricional da criança e do adolescente: Manual de Orientação. Rio de Janeiro: Sociedade Brasileira de Pediatria; 2009 [cited 2018 Sep 17]. Available from: http://www. sbp.com.br/fileadmin/user_upload/ pdfs/MANUAL-AVAL-NUTR2009.pdf

17. Frisancho AR. Anthropometric Standards for the Assessment of Growth and Nutritional Status. Ann Arbor: University of Michigan Press; 1990.

18. World Health Organization. WHO Child Growth Standards: length/ height-for-age, weight-for-age, weightfor-length, weight-for-height and body mass index-for-age: methods and development. Geneva: WHO; 2006.

19. World Health Organization. WHO Child Growth Standards: head circumference-for-age, arm circumference-for-age, triceps skinfold-for-age, and subscapular skinfold-for-age: methods and development. Geneva: WHO; 2007.

20. Ministério da Saúde (BR), Conselho Nacional de Saúde. Resolução CNS № 466, de 12 de dezembro de 2012. Diário Oficial da União [Internet] 2012 [cited 2018 Sep 19];1:59. Available from: https://bvsms.saude. gov.br/bvs/saudelegis/cns/2013/ res0466 12 12 2012.htm 
21. Brinksma $A$, Huizinga $G$, Sulkers $E$, Kamps W, Roodbol P, Tissing W. Malnutrition in childhood cancer patients: a review on its prevalence and possible causes. Crit Rev Oncol Hematol. 2012;83(2):249-75.

22. Orgel E, Tucci J, Alhushki W, Malvar J, Sposto R, Fu CH, et al. Obesity is associated with residual leukemia following induction therapy for childhood B-precursor acute lymphoblastic leukemia. Blood. 2014;124(26):3932-8.

23. Orgel E, Mueske NM, Sposto R, Gilsanz V, Freyer DR, Mittelman SD. Limitations of body mass index to assess body composition due to sarcopenic obesity during leukemia therapy. Leuk Lymphoma. 2018;59(1):138-14.

24. Belle FN, Wenke-Zobler J, Cignacco E, Spycher BD, Ammann RA, Kuehni CE, et al. Overweight in childhood cancer patients at diagnosis and throughout therapy: A multicenter cohort study. Clin Nutr. 2019;38(2):835-41.

25. Brinksma A, Roodbol PF, Sulkers E, Kamps WA, de Bont ES, Boot AM, et al. Changes in nutritional status in childhood cancer patients: a prospective cohort study. Clin Nutr. 2015;34(1):66-73.

26. Withycombe JS, Smith LM, Meza JL, Merkle C, Faulkner MS, Ritter L, et al. Weight Change During Childhood Acute Lymphoblastic Leukemia Induction Therapy Predicts Obesity: A Report From the Children's Oncology Group. Pediatr Blood Cancer. 2014;62(3):434-9.

27. Tselovalnikova TY, Pavlova MG, Zilov AV, Mazerkina NA, Zheludkova OG, Arefyeva IA, et al. Growth disorders after treatment for acute lymphoblastic leukemia in childhood. Vopr Onkol. 2016;62(6):817-21.

28. Orgel E, Genkinger JM, Aggarwal D, Sung L, Nieder M, Ladas EJ. Association of Body Mass Index and Survival in Pediatric Leukemia: a meta-analysis. Am J Clinical Nutr. 2016;103(3):808-17.

29. Zhang FF, Parsons SK. Obesity in Childhood Cancer Survivors: Call for Early Weight Management. Adv Nutr. 2015;6(5):611-9.
30. Teixeira JFC, Maia-Lemos PS, Cypriano MS, Pisani LP. The influence of antineoplastic treatment on the weight of survivors of childhood cancer. J Pediatr(Rio J). 2016;92(6):559-66.

31. Collins $L$, Beaumont $L$, Cranston $A$, Savoie S, Nayiager T, Barr R. Anthropometry in Long-Term Survivors of Acute Lymphoblastic Leukemia in Childhood and Adolescence. $J$ Adolesc Young Adult Oncol. 2017;6(2):294-8.

32. Saraiva DCA, Afonso WV, Pinho NB, Peres WAF, Padilha PC. Equivalência Semântica do Questionário Pediatric Subjective Global Nutritional Assessment para Triagem Nutricional em Pacientes Pediátricos com Câncer. Rev Nutr. 2016;29(2):211-27.

33. Saraiva DCA, Afonso WV, Pinho NB, Peres WAF, Padilha PC. Adaptação transcultural e validação do conteúdo em português da Pediatric Subjective Global Nutrition Assessment em pacientes pediátricos hospitalizados com câncer. Rev Nutr. 2017;30(3):307-20.

Received: Jul 5, 2020 Accepted: May 4, 2021 